\title{
VENOUS PRESSURE MEASUREMENT IN EXCHANGE TRANSFUSION
}

\author{
BY \\ DENNIS COTTOM and MAUREEN YOUNG \\ From St. Thomas' Hospital, London
}

(RECEIVED FOR PUBLICATION AUGUST 5, 1964)

Exchange transfusion in small infants carries a mortality of $4-7 \cdot 5 \%$ (Van Praagh, 1961 ; Boggs and Westphal, 1960). Many factors such as hypocalcaemia, circulatory overloading, hyperkalaemia, acidosis, citrate toxicity may be responsible, and the mode of death, whatever the aetiology, is usually thought to be acute cardiac failure ( $\mathrm{O}^{\prime} \mathrm{Neill}$ and Gordon, 1959; Robinson and Barrie, 1963), and commonly the infant shows signs of cardiac failure at necropsy. When cardiac failure occurs the venous pressure, as measured through the exchange catheter, rises; however, central venous pressure will only be recorded if the catheter tip passes through the ductus venosus and into the inferior vena cava.

Recently three observers (Rudolph, Drorbaugh, Auld, Rudolph, Nadas, Smith, and Hubbell, 1961; Burnard and James, 1963; Jegier, Blankenship, and Lind, 1963) have shown that the mean venous pressure in the normal newborn infant, whether it be measured in the right atrium or the inferior vena cava, is approximately $0 \mathrm{~cm} . \mathrm{H}_{2} \mathrm{O}$ and similar to the central venous pressure in the adult; these pressures were measured with electrical manometers from catheters introduced through the umbilical vein and related to the sternal angle. Both Rudolph et al. and Jegier et al. noted that it was not always possible to pass a catheter through the ductus venosus and therefore, before any interpretation of venous pressure is made, it must be known with certainty that the catheter is in the inferior vena cava. The site of the catheter can be readily determined by watching for the pressure drop of $5-10 \mathrm{~cm} . \mathrm{H}_{2} \mathrm{O}$ as the tip is advanced from between 8 to $12 \mathrm{~cm}$. from the umbilicus; the respiratory pressure swings are also considerably larger in the thoracic inferior vena cava than in the portal sinus (Fig. 1).

The data reported below confirm the findings just described and give some indication of the expectancy of passing an umbilical vein catheter through the ductus venosus during the first two days of life.
Methods and Material

The observations were made on 32 infants, 1 hour to 31 hours old, and ranging from $2 \cdot 3-5 \cdot 8 \mathrm{~kg}$. in weight. They were part of a study of hypoglycaemia of the newborn in which glucose was given parenterally and blood samples taken from the umbilical vessels; at the time the venous pressure was measured the infants were considered to be normal from the circulatory standpoint. Parental permission was always obtained from one or both parents when normal babies were investigated.

The venous pressure was measured with a New Electronic Products (N.E.P.) inductance manometer; the recordings were made with the N.E.P. recorder through pencil-type mirror galvonometers with an ultraviolet light source and print-out recording paper. The manometer was approximately level with the heart. The catheter was filled with heparin saline $(0 \cdot 25 \mathrm{ml} .5,000$ i.u. $/ \mathrm{ml}$. heparin in $100 \mathrm{ml}$. saline). The frequency response of the catheter manometer system was 30 cycles/second.

The observations were made in the premature baby nursery using sterile technique; the room temperature was $76^{\circ} \mathrm{F}$. $\left(24^{\circ} \mathrm{C}\right.$.). The infants were clothed and lay comfortably in the supine position on a mattress on a

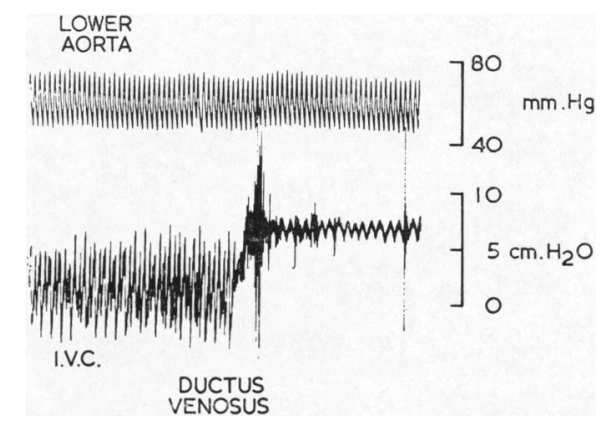

Fig. 1.-The lower pressure tracing shows, from left to right, (a) the relatively large respiratory pressure swings around the mean of zero recorded from the inferior vena cava above the ductus venosus; (b) a disturbance as the catheter is drawn through the ductus venosus; and (c) the small respiratory pressure swings around the mean of $7 \mathrm{~cm}$. $\mathrm{H}_{2} \mathrm{O}$ in the umbilical vein below the ductus venosus. The upper pressure trace is from the lower aorta. 
small instrument table to which they were lightly bandaged. A No. 6 (F.G.) 'Portex' catheter with 2 side holes, attached by a short length of saline-filled polythene tubing to the manometer, was introduced into the umbilical vein. It entered easily for the first $8 \mathrm{~cm}$. until the ductus venosus was reached. In two-thirds of the infants the catheter tip passed through a slight resistance when a pressure drop and more marked respiratory fluctuations were observed. In the remaining one-third this was not possible, and no pressure drop was observed; occasionally a little blood flowed back around the catheter when its tip coiled in the sinus below the ductus venosus.

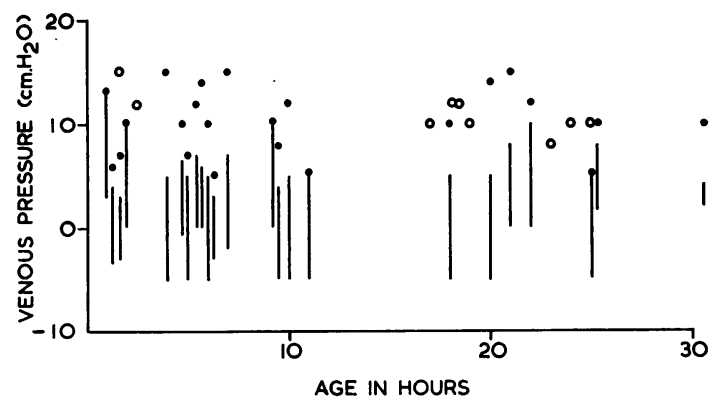

Fig. 2.-To demonstrate the different relationships between the mean pressure in the umbilical vein below the ductus venosus, and in the inferior vena cava above the ductus venosus, in 31 infants. In 9 of these it was impossible to pass the catheter beyond the ductus venosus. Pressure in IVC, vertical lines; in portal sinus ; and in portal sinus when ductus impassable $\bigcirc$.

\section{Results}

The venous pressure measured in the portal sinus below the ductus venosus ranged from +5 to $15 \mathrm{~cm}$. $\mathrm{H}_{2} \mathrm{O}$, with an average of $9 \cdot 9(\mathrm{SD} \pm 3 \cdot 2) \mathrm{cm} . \mathrm{H}_{2} \mathrm{O}$; respiratory swings of only $2-4 \mathrm{~cm} . \mathrm{H}_{2} \mathrm{O}$ were observed. In the inferior vena cava the mean pressure ranged from +5 to $-0.5 \mathrm{~cm} . \mathrm{H}_{2} \mathrm{O}$ with an average of $+1 \cdot 4(\mathrm{SD} \pm 2 \cdot 0) \mathrm{cm} . \mathrm{H}_{2} \mathrm{O}$; the respiratory fluctuations were large and ranged from 5 to 13 $\mathrm{cm} . \mathrm{H}_{2} \mathrm{O}$, as observed by Boggs and Westphal (1960). It was possible to pass the catheter through the ductus venosus in 22 out of 31 infants and a record of the pressure drop is shown in Fig. 1. The 9 failures to reach the inferior vena cava with the catheter advanced $10-12 \mathrm{~cm}$. from the umbilicus occurred most frequently in infants over 18 hours of age (Fig. 2).

\section{Discussion}

It was not possible to introduce a catheter beyond the ductus venosus in $30 \%$ of cases, a figure similar to that found by Rudolph et al. (1961) during the first 2 days of life. A recent necropsy study by Lind (unpublished observations) has demonstrated that this may be due to absence of the ductus venosus, a particularly small lumen, or an abnormal anatomical arrangement. Peltonen and Hirvonen (1963) have demonstrated by angiography that the ductus venosus may be open in vivo 12 days after birth.

The high venous pressure figures acceptable as normal in infants (Mollison and Cutbush, 1949; Bonham Carter, Bound, and Smellie, 1956) and during exchange transfusion (Boggs and Westphal, 1960; Walker and Neligan, 1955; Wright, 1961; Farquhar and Smith, 1958) suggest that the measurements have been made with the catheter tip in the portal sinus. Farquhar and Smith (1958) preferred this site for exchange transfusion since they had encountered cyanosis in the lower limbs, which they thought was due to spasm of the inferior vena cava if the catheter was advanced more than 7 to $8 \mathrm{~cm}$. from the umbilicus. The disadvantages of having the catheter in the portal sinus below the ductus venosus are twofold. First, it is possible that the perfusion of the slightly acid stored blood directly into the liver may be a factor in the development of portal vein thrombosis reported by Tizard (1962) and Oski, Allen, and Diamond (1963); in a recent study of the aetiology of portal vein thrombosis Thompson and Sherlock (1964) found no relationship to exchange transfusion. Secondly, it is difficult to interpret the venous pressures measured because the relation between central venous pressure and pressures measured in the portal sinus has not been fully explored. Our findings suggest that there is no constant relation between central venous pressure and pressure in the portal sinus, but the readings have not been compared over a wide range of pressures in the same infant.

It is usually assumed that the venous pressure will rise in the infant with inadequate cardiac function as it does in the adult, and may be a warning of early cardiac failure. For this reason the blood volume is frequently reduced during an exchange transfusion. The extrapolation from adult to infant may not, however, be justified. Moss and Duffie (1962) did not observe a raised right atrial pressure in infants of up to 2 years of age with other clinical signs of congestive cardiac failure. Both Burnard and James (1963) and Jegier et al. (1963) observed only a small rise in venous pressure lasting 6 hours in infants who had a blood transfusion from the placenta, equal to about $50 \%$ of their blood volume at birth. Further, Burnard and James (1963) found particularly low venous filling pressures in asphyxiated infants with enlarged hearts. The absence of an expected rise in venous pressure in the newborn might be due to the distribution of high venous filling pressures between both auricles, while the foramen ovale is patent, and to relative inactivity of reflex venous control at this age (Sharpey-Schafer, 1963). The 
latter is suggested because both baroreceptor and chemoreceptor reflex regulating mechanism appear to be relatively unreactive in the newborn period (Young and Cottom, unpublished observations). It is also possible that the venous pressure measurements during cardiac failure in infants are incorrect, for tachypnoea is also commonly present and the mean intrathoracic pressure is therefore likely to be low. Measurements of intraoesophageal pressure simultaneously with the inferior venal caval pressures will be needed to obtain the true venous filling pressure.

\section{Summary}

Catheterization of the inferior vena cava through the umbilical vein and ductus venosus was possible in $60 \%$ of 31 infants, $1-31$ hours old.

In confirmation of other workers, the mean central venous pressure at heart level was similar to that found in the adult, but the respiratory swings were frequently as large as $13 \mathrm{~cm} . \mathrm{H}_{2} \mathrm{O}$; the mean pressure below the ductus venosus in the portal sinus was +7 to $+10 \mathrm{~cm} . \mathrm{H}_{2} \mathrm{O}$.

No relation was observed between the pressures measured in the inferior vena cava and the portal sinus. The latter should not be used as a substitute for central venous pressure in assessing the 'deficit' with which the baby should be left at the end of exchange transfusion.

We are most grateful for the interest and co-operation of the nurses in charge of the Premature Baby Unit, Nurse Theodosius, Nurse Bywaters, and Nurse MillerJones.

This investigation was supported by the Endowment Funds of St. Thomas' Hospital, to whom we offer our thanks.
Dr. M. Young also wishes to acknowledge a grant from the National Spastics Society for the support of Miss Audrey Butler who gave invaluable technical assistance.

\section{REFERENCES}

Boggs, T. R., Jr., and Westphal, M. C., Jr. (1960). Mortality of exchange transfusion. Pediatrics, 26, 745.

Bonham Carter, R. E., Bound, J. P., and Smellie, J. M. (1956). Mean venous pressures in the first hours of life. Lancet, 2, 1320.

Burnard, E. D., and James, L. S. (1963). Atrial pressures and cardiac size in the newborn infant. J. Pediat., 62, 815 .

Farquhar, J. W., and Smith, H. (1958). Clinical and biochemical changes during exchange transfusion. Arch. Dis. Childh., 33, 142.

Jegier, W., Blankenship, W., and Lind, J. (1963). Venous pressure in the first hour of life and its relationship to placental transfusion. Acta paediat. (Uppsala), 52, 485.

Mollison, P. L., and Cutbush, M. (1949). Haemolytic disease of the newborn: Criteria of severity. Brit. med. J., 1, 123.

Moss, A. J., and Duffie, E. R. (1962). Congestive heart failure in infancy: significance of the venous pressure. J. Pediat., 60, 346.

O'Neill, E. M., and Gordon, R. R. (1959). Extended exchange transfusion in pre-hydropic infants. Arch. Dis. Childh., 34, 174.

Oski, F. A., Allen, D. M., and Diamond, L. K. (1963). Portal hypertension-a complication of umbilical vein catheterization. Pediatrics, 31, 297.

Peltonen, T., and Hirvonen, L. (1963). The ductus venosus. Acta paediat. (Uppsala), 52, 202.

Robinson, A., and Barrie, H. (1963). The electrocardiogram during exchange transfusion. Arch. Dis. Childh., 38, 334.

Rudolph, A. M., Drorbaugh, J. E., Auld, P. A. M., Rudolph, A. J., Nadas, A. S., Smith, C. A., and Hubbell, J. P. (1961). Studies on the circulation in the neonatal period. Pediatrics, 27, 551.

Sharpey-Schafer, E. P. (1963). Venous tone: effects of reflex changes, humoral agents and exercise. Brit. med. Bull., 19, 145.

Thompson, E. N., and Sherlock, S. (1964). The etiology of portal vein thrombosis with particular reference to the rôle of infection and exchange transfusion. Quart.J. Med., 33, 465.

Tizard, J. P. M. (1962). Portal hypertension following exchange transfusion through the umbilical vein. Proc. roy. Soc. Med., $55,772$.

Van Praagh, R. (1961). Causes of death in infants with hemolytic disease of the newborn (erythroblastosis fetalis). Pediatrics, 28, 223.

Walker, W., and Neligan, G. A. (1955). Exchange transfusion in haemolytic disease of the newborn. Brit. med. J., 1, 681 .

Wright, T. (1961). A new technique in exchange transfusion. Arch. Dis. Childh., 36, 400 . 